\title{
Building nations after conflict
}

\author{
Fixing Failed States: A Framework for \\ Rebuilding a Fractured World \\ by Ashraf Ghani and Clare Lockhart \\ Oxford University Press: 2008 \\ 264 pp. \$24.95, £14.99
}

Political instability in collapsed or collapsing states is one of the greatest sources of human misery. Since the end of the cold war, withinstate conflicts, such as civil wars and separatist rebellions, have caused ten times more deaths than have wars between states. The indirect, non-military consequences of internal conflict - civilian casualties, refugees, wrecked economies, famine and disease - are orders of magnitude worse than the direct, military outcomes. In Fixing Failed States, former Afghan finance minister Ashraf Ghani and development-policy expert Clare Lockhart analyse why states crumble and propose a framework for rebuilding state capability.

International organizations, such as the United Nations, International Monetary Fund and World Bank, have been busy recently. Before 1990, the United Nations initiated a peace-keeping mission on average once every three years. Since 1990, they have run approximately three new missions each year. Many interventions successfully stopped active fighting. Yet our record in addressing the deep causes of conflict and constructing viable postconflict societies has been poor.

Ghani and Lockhart are optimistic that we have "the elements of a new approach to state building". They review four examples - postwar Europe, Singapore, the southern United States and Ireland - that, in their opinion, prove that countries confronted with devastation, chaos and entrenched poverty can transform themselves into prosperous and stable members of the global community. Apart from Singapore, however, these are not examples of state collapse. Europe in 1945 was devastated by interstate war; Ireland was poor before its economic miracle but not a collapsed state; and few would consider the United States to be weak. Seceding from the Federation of Malaysia in 1965, Singapore was plagued by poverty, corruption and a communist insurrection. Today, it is an economic powerhouse with one of the least corrupt civil services in the world.

A better example, dealt with in passing, is the remarkable reversal of China's fortunes during the twentieth century. We think of China now as a surging world power that has enjoyed $10 \%$ annual economic growth since 1980 . Yet in the 1920s and 1930s, China was a collapsed state. With a weak national government and most of its territory controlled by warlords, it was affected by incursions from Europe and Japan, and by a raging communist uprising.

Can general lessons be drawn? Ghani and Lockhart fail to present a compelling analysis, quoting instead political leaders ranging from UK prime ministers William Gladstone and Gordon Brown to Mahathir Mohamad, former prime minister of Malaysia.

The authors do not use knowledge accumulated by social scientists in recent decades. There is no mention of the burgeoning literature on revolutions and state collapse, such as the work of sociologist Jack Goldstone, or of books on transitions from civil war to democracy, such as Elisabeth Jean Wood's Forging Democracy from Below (Cambridge University Press, 2000).

Such recent studies indicate that generalities can be found in the historical record, although we are only beginning to understand them. One generality that might have been included is the role of political élites in state building. When élites are fragmented - perhaps by ethnic divisions or rival patronage networks - each faction focuses on getting its own piece of the common pie instead of increasing the total size of the pie. Conflict among élites prevents consistent government policy and often mutates into an armed struggle. A necessary condition of a strong, effective and democratic state is some degree of consensus among the élites about the strategic goals and the political process for achieving them.

One of the most important social mechanisms that determines whether élites are consolidated or fragmented is élite overproduction - growing numbers of aspirants for élite positions, resulting from demographic expansion and unbalanced social mobility. When the number of aspirants greatly exceeds the supply of élite positions, fragmentation and conflict ensue.

Another important issue is cooperation and trust. A dysfunctional state is like a vast game of prisoner's dilemma in which those who cooperate are taken advantage of, leaving withdrawal from cooperation as the only rational strategy. Citizens avoid paying taxes because this will only enrich corrupt officials, whereas officials spend public money on themselves and their clans because if they do not, others will take it. How can societies escape such a state of pervasive distrust? We lack a good theory to provide an answer, but there are promises of one.

The new discipline of experimental economics demonstrates how non-cooperative groups

\section{Winning Darwin design takes root}

Sculptor Tania Kovats has won the Darwin's Canopy competition to design a new permanent artwork for Charles Darwin's bicentenary at the Natural History Museum in London. A longitudinal cross section of a real fallen oak tree, including roots, trunk and branches, will be veneered into the panelled ceiling of a gallery behind the central hall.

Ten contemporary artists submitted designs, which are on display at the museum until 14 September. Kovats's ceiling installation will be unveiled on 12 February 2009, on what would have been Darwin's twohundredth birthday.

Kovats, currently tracing Darwin's footsteps in South America, has long marvelled at a piece of petrified tree held at the museum. $A$ branching sketch in Darwin's notebook of 1837 also

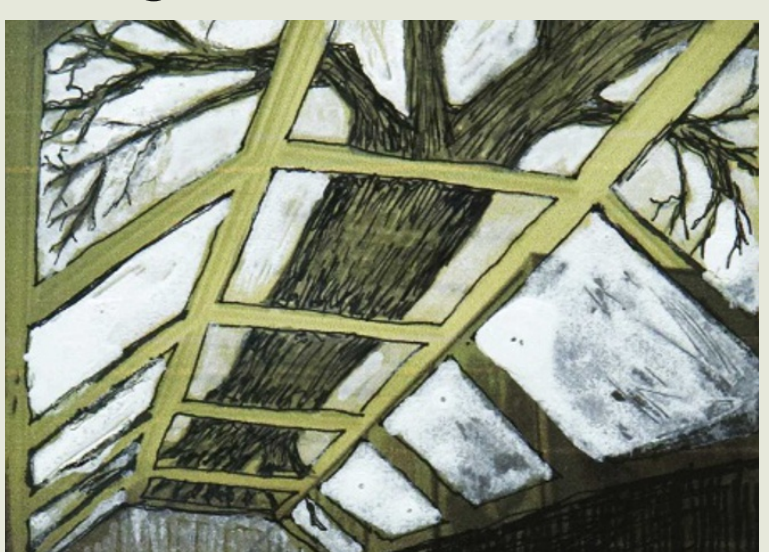

inspired her. "Whether a tree or a coral," she notes, it is "quite remarkable for how it represented to him a proof of where his thoughts were going".

Within Kovats's design (sketch, pictured), her tree's roots will represent the research of museum scientists. Its branches will represent the museum's role in disseminating knowledge, as well as taxonomy, and the use of a fallen tree hints at how Darwin felled the existing orthodoxy. The tree "is a real thing as well as a sculptural intervention, and as such can take its place amongst the other real things housed in the collection", she explains. Colin Martin is a writer based in London. 
can shift to being cooperative by applying moralistic punishment, such as sanctions, against defectors. On a national scale, history suggests that external pressure applied to a society may increase internal cohesion and cooperation. National humiliation of China, first from the European great powers in the nineteenth century and then from Japanese occupation during the Second World War, played an important part in its post-war reunification, for example.

The policy implications of historical outcomes are doubtful. We can hardly subject societies to horrific stresses deliberately, and they may produce oppressive regimes in response. Rather than focus on a few haphazard cases, systematic research is needed to find out what works. Although not mentioned in Failed States, such programmes are currently being conducted by, for example, the Political Instability Task Force in the United States and the Centre for the Study of Civil War in Oslo, Norway.

Ghani and Lockhart propose an agenda for state building, but their weak analysis undermines its credibility. They suggest a 'sovereignty strategy' that involves formulating a strategy, then setting the goals and rules of the game, mobilizing resources, allocating critical tasks and, finally, monitoring implementation of the strategy. This generic approach does not suggest concrete policies. For example, the book describes how a strategy formulated in the Indian state of Andhra Pradesh "forced a sobering reading of conditions: corruption, inefficient use of state resources, short-term planning and poor infrastructure. This reading of context enabled participants to embrace change and leaders to set a clear sense of direction." Given such an easy buy-in, one wonders why this approach has not enabled more sides, such as the Maronite Christians and the Shia and Sunni Muslims in Lebanon, to make peace given the many opportunities they have had to "embrace change".

I nonetheless commend Ghani and Lockhart for raising this issue. We cannot afford to ignore failed states. We insist that new drugs are exhaustively tested before they are used, so shouldn't we invest in better social science before we intervene with failed states? Otherwise, our well-intentioned but misguided attempts to fix them may be as helpful as the medieval practice of blood-letting.

Peter Turchin is professor at the Department of Ecology and Evolutionary Biology,

University of Connecticut, Storrs, Connecticut 06269-3043, and author of War and Peace and War.

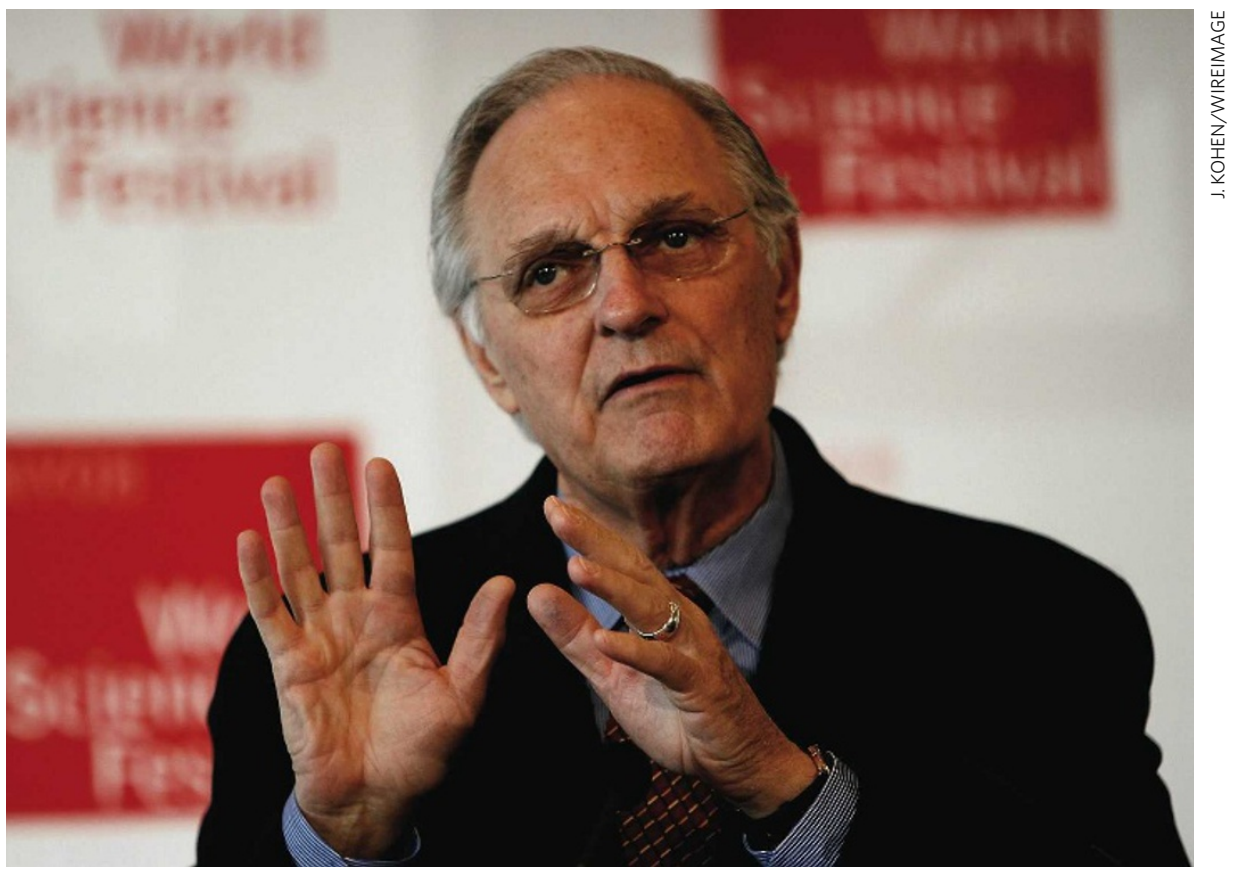

\section{Q\&A: Insight into Einstein}

Actor Alan Alda, who starred in the television series $M^{\star} A^{\star} S^{\star} H$ and now hosts Scientific American Frontiers on US network PBS, is fascinated with physics. At last month's World Science Festival in New York he led a panel discussing the quantum world, portrayed Richard Feynman in the play QED, and presented Dear Albert, his new play drawn from Albert Einstein's letters.

\section{Why did Einstein's letters interest you?} It's very important for us to see that science is done by people, not just brains but whole human beings, and sometimes at great cost. Letters can be very personal, and sometimes confrontational.

I had also planned to write a play about Marie Curie's letters. I got a little discouraged because not only are they in Polish and French, but the French letters are still slightly radioactive. After you look at them they go over you with a Geiger counter. I thought I'd wait until somebody else goes in a hazmat suit and translates them. So I stuck with Einstein.

Einstein emerges from your play as a highly
volatile character, sometimes spiteful and
domineering, sometimes withdrawn and
resigned. How do you see him?
Einstein claims not to have felt lonely, but he
was a lonesome figure. He could see far out
into the cosmos but he was myopic about
the people next to him. It was difficult for
him to take the time for what he called the
"merely personal". And he really did seem
to take refuge in these very complicated

images in his head. Like Feynman, he challenged every idea that came to him. He wanted to rethink it, he wanted to see more deeply into it.

\section{Why did you focus on Einstein's relationships with his two wives, Mileva and Elsa?}

Plenty of his correspondence with colleagues was about the science that he was working so hard on. But I wanted to show the personal side of the discoveries and ruminations. For somebody with hair like that, he did awfully well with the women. At one point he couldn't decide whether to marry his second wife Elsa or her daughter Ilse, who wrote to a friend, "Albert refuses to take a position on this".

\section{Will the play be performed again?}

I don't know. It was like a high-energy experiment: we just let the actors collide with the material. Whatever particles came out of it we could observe for a short time, and now it has evaporated.

Interview by Jascha Hoffman, a writer based in New York. 